\title{
Features of atmospheric disturbances in temperate latitudes before strong earthquakes $(M>7)$ according to satellite measurements
}

\author{
Valentin Kashkin ${ }^{1}$, Leonid Sverdlik $^{2}$, Roman Odintsov ${ }^{1}$, Tatyana Rubleva ${ }^{1}$, Konstantin \\ Simonov $^{3}$, Alexey Romanov and Sanjar Imashev $^{2}$ \\ ${ }^{1}$ Siberian Federal University, Krasnoyarsk, 660074, Russia \\ ${ }^{2}$ Research Station of the Russian Academy of Sciences in Bishkek, Kyrgyzstan \\ ${ }^{3}$ Institute of Computational Modeling SB RAS, Krasnoyarsk, Russia
}

\begin{abstract}
An ATOVS and MERRA data archive containing temperature values at isobaric levels from 1000 to $50 \mathrm{hPa}$ was formed to study the atmospheric effects observed over the foci of two strong earthquakes with magnitudes $M=7,3$. The first seismic event was recorded on August 19, 1992 in the northern Tien Shan and the second on November 12, 2017 in the border areas of the Zagros folded mountain belt. According to USGS intense aftershock activity in these regions began with these seismic events. Using correlation and spectral analysis we studied the vertical profiles of temperature and pressure in a disturbed atmosphere over seismically active regions. The modified anomaly index was calculated at isobaric levels from 500 to $50 \mathrm{hPa}$ and on its basis the registered temperature anomalies were investigated.
\end{abstract}

\section{Introduction}

Using remote sensing data makes it possible to solve the problems of monitoring atmospheric phenomena observed in the geological environment during seismic processes. These are atmospheric effects over fault zones of the earth's crust in the form of perturbations of meteorological fields and temperature anomalies [1, 2]. In [1] it is indicated that the movements of the earth's crust excite internal gravitational waves in the atmosphere. These processes are accompanied by various variations of geophysical fields and contain valuable information about the features of the observed anomalous phenomena. In this regard, it becomes relevant to study the interaction of the lithosphere-atmosphere during geodynamic activity.

In our work according to the satellite equipment ATOVS (Advanced TIROS Operational Vertical Sounder, KA NOAA / POES, USA) and the global reanalysis database MERRA (Modern-Era Retrospective Analysis for Research and Applications, NASA), available on sites [3, 4]. The atmospheric temperature variations during the sharp activation of seismic processes are analyzed. At that time in the mountainous regions of the northern Tien Shan (Kyrgyzstan) on August 19, 1992 and in the northwest of the Zagros mountain belt (Iraq-Iran) on November 12, 2017 strong earthquakes with magnitude $\mathrm{M}=7,3$ were recorded. 


\section{Seismic data}

In the mountainous region of the northern Tien Shan a strong earthquake of magnitude $\mathrm{M}=7,3$ occurred at 02:04:37 UTC on August 19, 1992 [5]. Note that the northern Tien Shan is a seismically active intracontinental mountain belt located in the zone of collision of the Eurasian and Indian lithospheric plates. However, the epicenter of the main shock with coordinates $\left(42.142^{\circ} \mathrm{N} ; 73.575^{\circ} \mathrm{E}\right)$ was in the seismically weakly active region of the Suusamyr depression. The focus of the hypocenter was located at a depth of about $27 \mathrm{~km}$.

A fragment of the map of the aftershock field of the Suusamyr earthquake is shown in Fig. 1, $a$. After the seismic event $M=7,3$, three strong aftershocks $(M \geq 6,1)$ occurred in the area within 50 minutes, which arose in the Earth's crust with boundaries of 18.5-33.0 km. In total, during the day, August 19, 1992, 20 aftershocks with magnitudes of $3,8<\mathrm{M}<6,3$ were recorded here. Only by the end of 1993 as follows from the data of [6] the seismicity in the study area gradually began to decrease to background values.

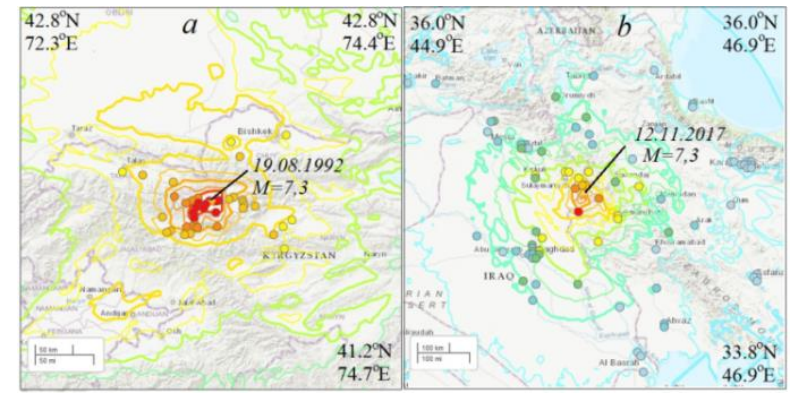

Fig. 1. Aftershock field of the earthquake August 19, 1992 in the northern Tien Shan $(a)$ and location of the aftershock field of the seismic event November 12, 2017 in the Iraq-Iran $(b)$

The second seismic event of magnitude $\mathrm{M}=7,3$ (Fig. 1, $b$ ) occurred on November 12, 2017 at 18:18:17 UTC in the north-west of another intracontinental mountain belt Zagros located in the Middle East in the border regions of Iraq-Iran [7, 8] . As indicated in [7] the fold-thrust belt Zagros was formed as a result of a collision of the Arabian and Eurasian tectonic plates. Undoubtedly, the seismicity of the area where a strong earthquake $M=7,3$ occurred is directly related to the geodynamic processes in the zone of collision of these two plates. The aftershock field of this strong earthquake is shown in Fig. $1, b$. The epicenter of the main shock with coordinates $34.91^{\circ} \mathrm{N}$ and $45.96^{\circ} \mathrm{E}$ was located $29 \mathrm{~km}$ south of the city of Halabadjan (Iraq) [7]. The hypocenter of the earthquake $\mathrm{M}=7,3$ was at a depth of $\sim 19 \mathrm{~km}$. According to the USGS we determined the boundaries of the peak region of the Iraq earthquake. Its dimensions in latitude were $33.8-36.0^{\circ} \mathrm{N}$ and in longitude $44.9-46.9^{\circ} \mathrm{E}$.

Analysis of the seismic data [5] of the aftershock field of the Iraq earthquake showed that the geodynamic activity in the studied peak region began with the earthquake $M=4,1$ recorded on November 3, 2017 at 10:33:41 UTC. Over the next 9 days no seismic events were recorded in this area, i.e. seismic lull was observed. Only on November 12, 201740 minutes before the main shock at 17:35:31 UTC a new foreshock of magnitude $M=4,6$ was registered here. In total in November 201740 aftershocks occurred in the focus of this earthquake. The depths of their hypocenters varied between $7.0-19.0 \mathrm{~km}$. The highest seismic activity in the peak region according to the USGS was observed in 2018. This year 73 earthquakes with magnitudes of $3,7<\mathrm{M}<6,3$ occurred here. 


\section{Satellite data and analysis technique}

The study of atmospheric disturbances over the studied seismic regions was carried out according to the ATOVS and MERRA data [3, 4]. ATOVS satellite information is obtained from measurements with HIRS-4 AMSU-(A, B) and MHS instruments. Temperature profiles were restored using the IAPP (International ATOVS Processing Packages) software package by solving the inverse problem [3]. ATOVS data has a spatial resolution of $1^{\circ} \times 1^{\circ}$ in latitude and longitude. As a result we formed temperature series on isobaric surfaces from 1000 to $100 \mathrm{hPa}$ with a time step of 3 hours. The standard deviation of ATOVS data in temperature from the results of measurements of radiosondes is $1.3 \mathrm{~K}$.

The MERRA global meteorological reanalysis database is a modern global model of GMAO (Global Modeling and Assimilation Office) which is constantly being adjusted taking into account satellite measurements of the GEOS-5 (Goddard Earth Observing System, NASA) and the results of observations of a network of ground stations in order to ensure reliability forecast calculations [4]. MERRA data have a spatial resolution of $0.5^{\circ} \times 0.675^{\circ}$ (latitude-longitude) .

The technique of processing temperature series was considered in detail in $[2,8]$. It is based on the correlation and spectral analysis of temperature profiles in atmospheric layers from the underlying surface to the lower stratosphere. Using our methodology we studied the features of the amplitude, frequency and phase of temperature variations observed before strong earthquakes. To detect temperature anomalies over areas where earthquakes are recorded the RST (Robust Satellite Techniques) method is widely used [9]. We calculated the modified anomaly index $\delta T$ for a perturbed atmosphere taking into account the measurement time and pressure at a certain isobaric level $[2,8]$. Then the integral indicator of temperature anomalies $D_{\delta T}$ was calculated which was found from the relation:

$$
D_{\delta T}=D I S P_{\delta T}^{u t} \cdot D I S P_{\delta T}^{t r},
$$

where $D I S P_{\delta T}^{u t}$ is the variance of the moving average series of the anomaly index $\delta T$ in the upper troposphere (upper troposphere - $u t$ ) and $D I S P_{\delta T}^{t r}$ is the variance of the moving average series of the $\delta T$ index in the tropopause (tropopause $-t r$ ).

The values of the integral parameter $D_{\delta T}$ exceeding unity indicate the presence of antiphase anomalous in amplitude temperature variations in both considered atmospheric layers. Further $D_{\delta T}$ values were compared with data on seismic activity in the studied areas.

\section{Temperature variations}

The application of the above methodology allowed us to identify common signs and features of atmospheric effects observed during the preparation of strong earthquakes with $\mathrm{M}=7,3$ in the northern Tien Shan and the folded mountain zone Zagros. Based on the obtained temperature profiles at isobaric levels from $500-50 \mathrm{hPa}$ atmospheric disturbances over areas of strong earthquakes were studied during the period of seismic processes in August 1992 and November 2017.

In Fig. 2, $a$ shows the temperature profiles $T_{300}$ at the isobaric level of $300 \mathrm{hPa}$ (upper troposphere) and $T_{100}$ at the level of $100 \mathrm{hPa}$ (lower stratosphere) during the preparation of the earthquake at the main seismic moment, and during aftershock activity over the seismically active region of the northern Tien Shan restored according to the data reanalysis MERRA. It was found that approximately 5-8 days before seismic events, positive temperatures $T_{100}$ and negative temperatures $T_{300}$ are observed. 
In Fig. 2, $b$ shows graphs of the dependence of temperature on pressure for August 9, 14 and 18, 1992 when preparing the main shock $M=7,3$. The most amplitude changes in temperature are found in the atmospheric layers of $300-250 \mathrm{hPa}$ and $150-100 \mathrm{hPa}$.

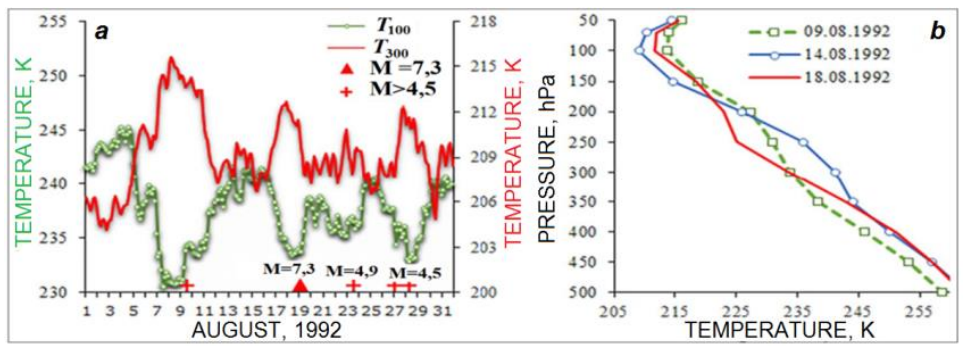

Fig. 2. Temperature series $T_{300}$ and $T_{100}$ in August $1992(a)$ and vertical temperature profiles before the Suusamyr earthquake $(b)$ according to MERRA

In Fig. 3, $a$ shows the graphs of the temperature series $T^{\prime}{ }_{300}$ (at the level $300 \mathrm{hPa}$ ) and $T^{\prime}{ }_{100}$ (at the level $100 \mathrm{hPa}$ ) in a disturbed atmosphere over the border regions of Iraq-Iran during the November 2017 seismic processes, constructed using ATOVS satellite data. The correlation coefficient between the series $T^{\prime}{ }_{300}$ and $T^{\prime}{ }_{100} R=-0.68$, consequently temperatures in the upper troposphere and lower stratosphere above the peak region of the Iraqi earthquake change in antiphase. The transition of the correlation function through " 0 " and a change in the sign of the correlation coefficient in the atmosphere disturbed by seismic events in the studied period of 2017 occurred near the tropopause in the transition zone of 300-200 hPa.

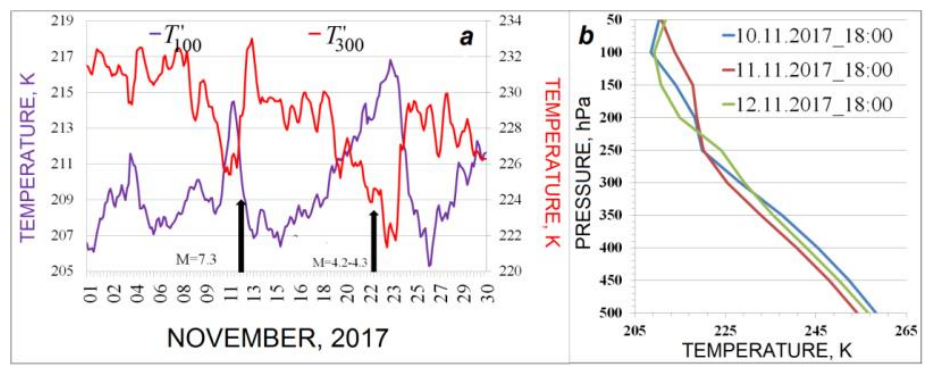

Fig. 3. Temperature series $T^{\prime}{ }_{300}$ and $T^{\prime}{ }_{100}(a)$ and temperature profiles before the Iraqi earthquake (b) in November 2017 according to ATOVS

If we consider temperature as a characteristic, then we can see the change in pressure over time in a disturbed atmosphere. In Fig. 3, $b$ show examples of vertical temperature profiles on November 10, 11 and 12, 2017. It was found that the most significant temperature changes occur in the atmospheric layer of 300-100 hPa.

In Fig. 4, $a$ shows the temperature series $T_{300}, T_{200}$ and $T_{100}$ for 1992 reconstructed according to the MERRA reanalysis, at the corresponding isobaric levels of 300, 200 and $100 \mathrm{hPa}$. It can be seen that from June to October 1992 antiphase temperature variations were observed.

In Fig. 4, $b$ shows a graph of the correlation coefficient between the series $d T_{300}$ and $d T_{100}$, characterizing the temperature increments $d T=T\left(t_{i+1}\right)-T\left(t_{i}\right)$ at isobaric levels of 300 and $100 \mathrm{hPa}$, respectively. Series $d T_{300}$ and $d T_{100}$ were calculated for the same time in a sliding window $m=40$ days. Before a strong earthquake on August 19 in Fig. 4, $b$ one can see a decrease in the correlation coefficient $R$ to 0.84 . This is probably due to two circumstances: either with an increase in the amplitude of temperature fluctuations or with the synchronism of antiphase temperature variations. 


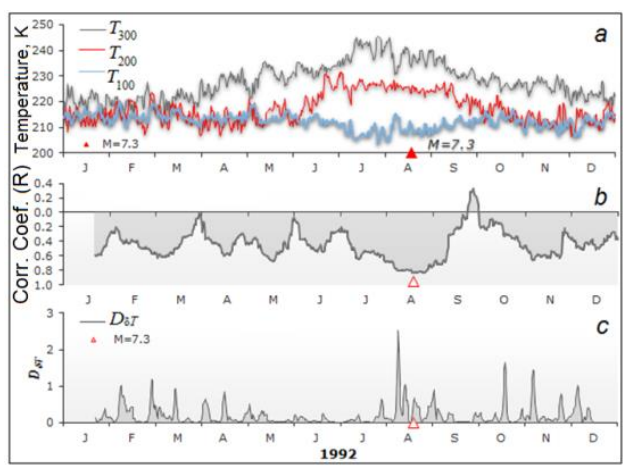

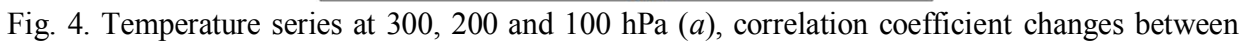
series $d T_{300}$ and $d T_{100}(b)$ and anomaly index variations $D_{\delta}(c)$ for 1992

In Fig. 4, $c$ graph of the $D_{\delta T}$ anomaly index for 1992 is shown in the layers separated by the tropopause of 300-250 hPa and 150-100 hPa. Values $D_{\delta T}$ were calculated for the same moment in a sliding window $m=10$ days. As can be seen in Fig. 4, $c$ in 8 days before the Suusamyr earthquake the $D_{\delta T}$ index increased to 2.5 .

\section{Temperature anomalies}

To detect anomalies observed over seismically active regions maps of the spatial distribution of daily average values of outgoing long-wave radiation (OLR) for August 1992 were constructed. Values $\delta \mathrm{W} D_{\delta T}$ for each pixel were determined using the RST method [9] as the deviation of the current value of OLR from its five-year average values for 1987-1991, normalized on the standard deviation $\sigma$.

In Fig. 5 shows examples of anomalies in the outgoing long-wave radiation for August 15 and 18. It was found that the OLR anomaly in Fig. 5, $a$ observed on August 15,1992 and exceeding the $2 \sigma$ level approximately repeated the location of active regional faults which are shown by dashed lines. This anomaly is elongated in the sublatitudinal direction. On August 18, 1992 about a day before the Suusamyr earthquake the OLR anomaly was recorded near the epicenter of the main seismic shock (Fig. $5, b)$.

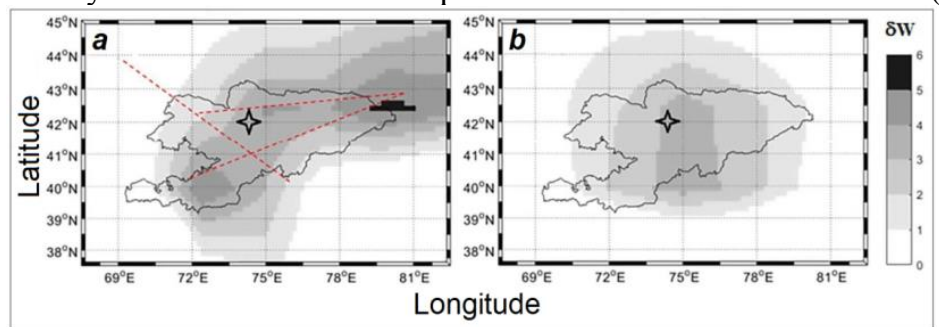

Fig. 5. OLR anomalies of near the epicenter of the earthquake on August $15(a)$ and August $18(b)$ 1992

In Fig. 6 shows examples of digital maps of the difference in temperature fields and the corresponding isotherms at $300 \mathrm{hPa}$ and $100 \mathrm{hPa}$ for November 12, 2017. The temperature field is shown at $25-45^{\circ} \mathrm{N}$ and $34-65^{\circ} \mathrm{E}$. The temperature deviation scale $\Delta T$ is shown on the right. The epicenters of strong earthquakes are indicated by bold dots, their focal areas are indicated by a solid line, and the preparation zones are indicated by a dashed line. Here you can see the temperature anomalies existing at this moment. 
In Fig. 6, $a$ the temperature deviation scale is designated as $\Delta T_{1-2}$ where $\Delta T_{1-2}=T_{1}-$ $T_{2}$. Here $T_{1}$ is the temperature in disturbed atmospheric conditions for November 12 , 2017 at an isobaric level of $300 \mathrm{hPa}$, and $T_{2}$ is the temperature at the same level for the background mode for November 12, 2016. The anomalous region with negative temperatures $\Delta T_{1-2}$ is shown in Fig. 6 a. It is oriented in the latitudinal direction to the west-east. The epicenter is in the area of condensation of isotherms.

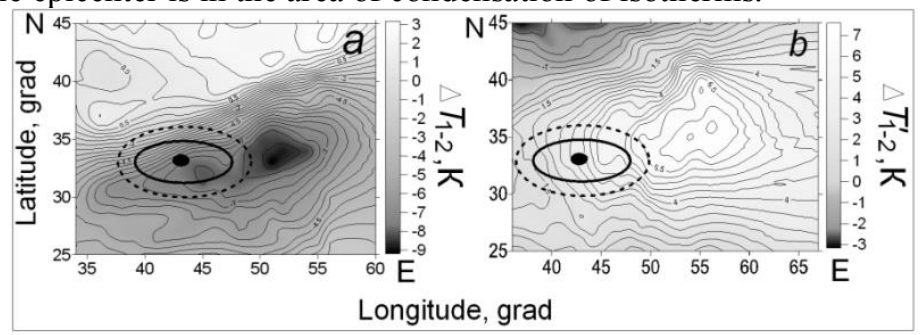

Fig. 6. Difference maps of the temperature field at the levels of $300 \mathrm{hPa}(a)$ and $100 \mathrm{hPa}(b)$ for November 12

In Fig. 6, $b$ the temperature deviation scale is designated as $\Delta T_{1-2}^{\prime}$ where $\Delta T_{1-2}^{\prime}=T_{1}^{\prime}{ }_{1}$ $T_{2}^{\prime}$. Here $T_{1}^{\prime}{ }_{1}$ is the temperature in disturbed atmospheric conditions for November 12 , 2017 at an isobaric level of $100 \mathrm{hPa}$ and $T_{2}^{\prime}$ is the temperature at the same level for the background mode for November 12, 2016. Anomaly with positive values $\Delta T_{1-2}^{\prime}$ is located in the lower stratosphere (Fig. $6, b$ ). It is also oriented in the latitudinal direction to the west-east.

\section{Conclusion}

Using remote sensing data makes it possible to solve the problems of monitoring atmospheric phenomena observed in the geological environment during seismic processes. These are atmospheric effects in the form of disturbances in the parameters of meteorological fields and temperature anomalies over fault zones of the earth's crust. The results of the study of temperature fields in the upper troposphere and lower stratosphere indicate the presence of a relationship between the observed disturbances in the atmosphere of temperate latitudes and the activation of seismic processes in areas belonging to two different mountain systems. The presented results are a continuation of the study of the disturbed atmosphere during seismic processes according to the data.

\section{References}

1. V.B. Kashkin, Atmospheric and Oceanic Optics 26, 10 (2013)

2. $\quad$ L.G. Sverdlik, S.A.Imashev, J. Sib. Fed. Univ. Eng. Technol.10, 6 (2017)

3. NOAA. URL: http://www.arl.noaa.gov/ready/cmet.html

4. NASA. URL: http://giovanni.gsfc.nasa.gov/

5. USGS. URL: https://earthquake.usgs.gov/earthquakes/map

6. Z.A. Kalmetieva, A.V. Mikolaichuk, and et al. Bishkek: CAIAG. (2009)

7. B. Mahani, A.J. Kazemian, J.Seismol. 22 (2018)

8. V.B. Kashkin, R.V. Odintsov, T.V. Rubleva, A.A. Romanov, K.V. Simonov, Trigger effects in Geosystems (Moscow, June 4-7, 2019): Materials of the V International Conference / M.:Torus Press (2019)

9. V. Tramutoli, V. Cuomo, C. Filizzola, N. Pergola, C. Pietrapertosa, Remote Sensing of Environment, 96, 3-4 (2005) 